\title{
EAl Endorsed Transactions

\section{Empowering HCI Students to Better Manage their Learning Process through a Flipped Classroom Experience}

\author{
Silvia Gabrielli ${ }^{1}$ \\ ${ }^{1}$ CREATE-NET, Via Alla Cascata 56/D, 38123 Trento, Italy
}

\begin{abstract}
This position paper presents observations from a flipped classroom experience of teaching an HCI bachelor course at the University of Trento (Italy) in Fall 2015.

Students were provided with conventional lectures, digital learning materials in Moodle, and a collaborative prototyping platform for supporting project work over the 2 -months course duration.

Overall, students highly appreciated the flexibility of having access to a combination of digital and conventional teaching resources. However, we observed a rather slow adoption of the remote collaboration features offered by the prototyping platform during the project work. This shows students' initial reluctance and lack of familiarity with using asynchronous communication-collaboration tools for better managing their group work and learning in blended education programs.
\end{abstract}

Keywords: Flipped Classroom, HCI Teaching, Persuasive Technologies, Case Study.

Received on 16 June 2016, accepted on 16 June 2016, published on 23 August 2016

Copyright (C) 2016 Silvia Gabrielli, licensed to EAI. This is an open access article distributed under the terms of the Creative Commons Attribution licence (http://creativecommons.org/licenses/by/3.0/), which permits unlimited use, distribution and reproduction in any medium so long as the original work is properly cited.

doi: 10.4108/eai.23-8-2016.151637

\section{Introduction}

The flipped classroom model of teaching has in recent years been proposes as an innovative method for better engaging students in active learning with respect to traditional teaching [1]. Such a method empowers students to take more responsibility over their learning experience, making it more meaningful and learnercentered. In a flipped classroom, content delivery may take a variety of forms, typically including video lessons prepared by the teacher or third parties, but also other resources such as online collaborative discussions, digital research, and text readings [2][3].

Flipped classrooms perfectly fit project-based learning, skill development or concept practice [4]. More time can be spent in class on higher-order thinking activities such as problem-solving, collaboration, design and students can tackle difficult problems, work in groups, research, and construct knowledge with the help of their teacher and peers [5].

Although differences can be found in the specific methods of implementation of flipped classrooms, a main benefit of their deployment is that teacher's interaction with students can be more personalized and less didactic, also students are actively involved in knowledge acquisition and construction as they participate in and evaluate their learning [6].

In this paper we present initial qualitative results from the application of a flipped classroom model to the teaching of an HCI bachelor course at the University of Trento (Italy), during Fall 2015.

The main research questions guiding our experimentation and analysis were the following:

- how can we effectively support students' engagement and active participation during the course, through project work, by providing a more personalized tutoring experience, which fits the different needs, background and learning styles of students?

- Which sets of coaching tools and motivational strategies are better able to match students learning needs and preferences over a flipped classroom experience on HCI?

The aim of the case study presented is to share results and stimulate discussion within the HCI community on current and future opportunities as well as main issues in the deployment of flipped classroom experiences in higher education settings.

"Corresponding author. Email: silvia.gabrielli@create-net.org 

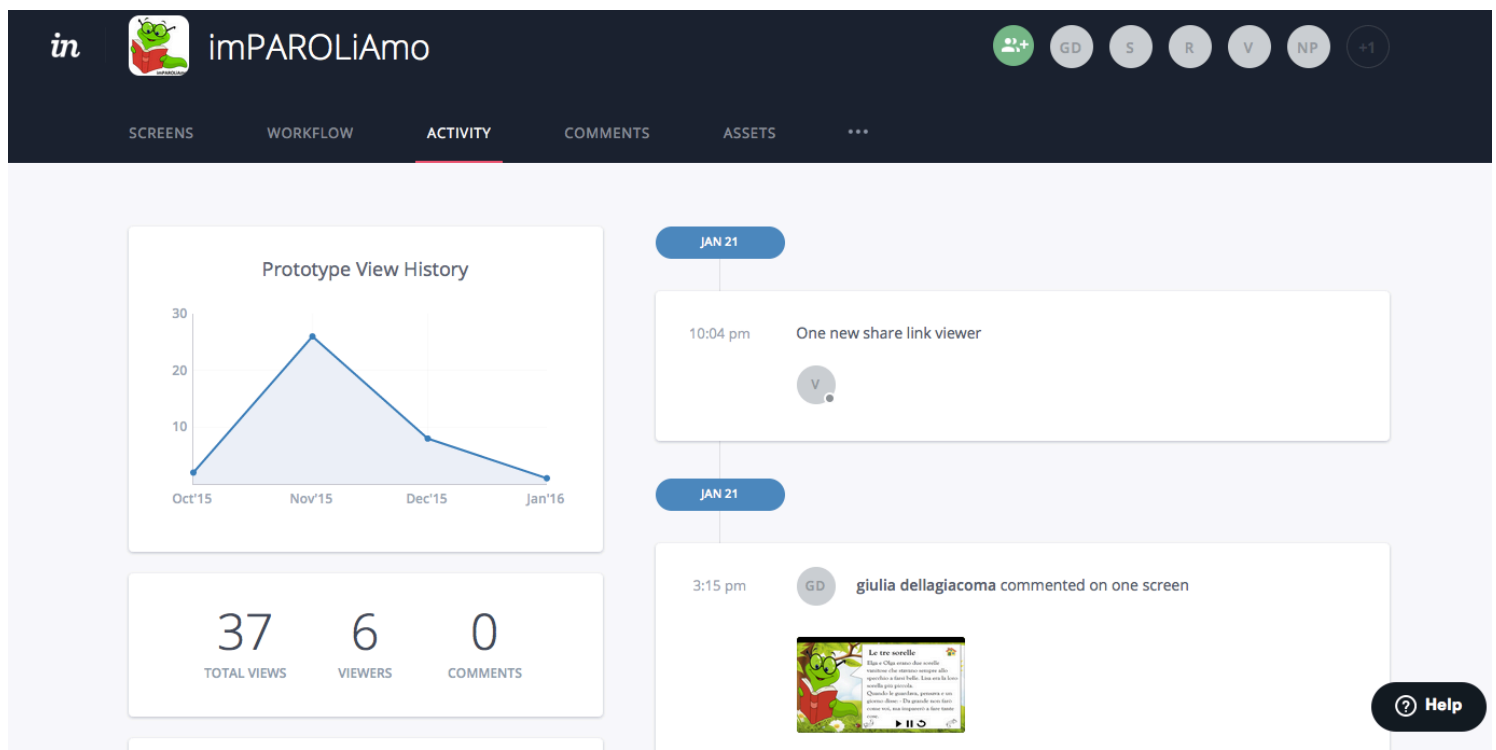

Figure 1. Screenshot showing data analytics regarding activities conducted during a students' project work

\section{Case Study}

The case study setting was a HCI bachelor course at the University of Trento, running during the second semester of 2015 for the duration of 8 weeks.

The course was attended by 47 students, but being attendance not compulsory, every year also a small percentage $(<5 \%)$ of non-attending students are giving the final examination. According to a flipping classroom model students are provided with course material in digital form available on a Moodle platform (including slides, assignments/exercises, case studies, links to relevant design resources and tools, etc.) that students can download/view anytime during the course to support their in/out of class learning of HCI basics and their projectbased activities. Class activities are concentrated in 1 half day per week (5 hours), and consist for $1 / 3$ of class discussion on theoretical/methodological basics of HCI, for $2 / 3$ of project work on User-Centered Design of mobile/web applications conducted in groups.

During the prototyping phases of project work, students develop wireframes of their applications by using JustinMind Prototyper platform, as well as the InVision collaborative platform to share design work within the team and to collect external feedback from tutors, users and other stakeholders. The InVision platform supports both teacher and students in monitoring progress with project work, by offering a dashboard presenting analytics on activity level, number of viewers, comments and other collaborative work conducted during the project (Fig.1). During the course students are encouraged to put in practice the knowledge acquired and to exchange feedback between teams about early design choices (e.g., each group invites external peers to conduct heuristic evaluations of their prototype, and at the same time performs heuristic evaluation of other teams' work).
Motivational strategies inspired by the field of persuasive technologies are deployed during the course to support students' engagement with the group activities and empowering students to better manage their learning process over the 8 weeks. As an example, the goal-setting strategy is deployed, by assigning to each team a project work to be performed in 8 different steps over the course. Social influence strategies are also deployed by stimulating competition and collaboration among teams over the projects' execution. Self-monitoring, rewarding and tailoring mechanisms are also provided by allowing students to be supported by online platforms and by teacher/tutor feedback in conducting their project work in face-to-face and remote conditions.

\section{Results}

A main result of this flipped classroom experience is that all 47 involved students completed their project work and presented their design project by the end of the course in a live, high quality presentation to the rest of the class. Attendance of the class activities was good and stable throughout the course, with limited absences of students mainly during the $1 / 3$ class-hours on discussion of HCI topics. Students did not show difficulties in managing their learning with the materials provided on Moodle, but showed a clear preference and interest for conducting the project work and getting tailored assistance by tutors in solving challenges encountered during their design activities.

Although the motivational strategies adopted during the course seemed to work well in supporting both individual and team interest over the 8 weeks, this was particularly true for the face-to-face class activities. In fact, we observed a relatively small usage of the self-monitoring and remote collaboration features provided by the 
InVision platform. This might be due to students' preference and familiarity with group design activities to be conducted face-to-face, but also to a lack of reinforcement and tailoring of self-monitoring features and data analytics to the specific needs of students during their learning process.

\section{Conclusions and Future Work}

The case study presented suggests some main opportunities and potential areas of improvement for the future design of flipped classrooms experiences in higher education.

Support of students' engagement and active participation: in the case presented it was easier to support students' engagement with the project work with respect to class discussions on HCI topics. A motivation for that could be that students' attention and interest were captured by the goal of realizing their design project and thus they dedicated limited resources to the preparation of class discussions during the course. A possible improvement in future editions of the course might consist in better structuring class discussions in the form of challenges that students need to tackle step by step to get some tangible achievements or rewards contributing to their final goal or examination outcome.

Personalized tutoring over class activities: it was easier to provide personalized tutoring fitting students' needs and learning styles as a support to project activities, since learners were more willing to disclose their difficulties and requests for support in the context of practical design choices and issues. Most of these interactions occurred in face-to-face class activities, while remote tutoring opportunities were underused.

Embedding motivational strategies in coaching and data analytics tools: motivational strategies inspired by persuasive technology design, such as goal-setting, selfmonitoring, tailoring and rewarding are powerful means that can be effectively deployed to raise and sustain learners' interest and motivation over educational experiences.
The case study presented showed that there is still room for future work exploring how to best incorporate motivational strategies in the design of digital tools, data analytics features and collaborative platforms used by teachers and learners in flipped classroom experiences. As an example, the type of activity tracking features and their level of detail need to be better adapted to students and teachers' needs, in order to effectively support selfmonitoring or supervision, in a way that they can be perceived as meaningful and useful to support improvement of the learning/teaching process over a course duration and beyond.

It is a particularly stimulating opportunity for the HCI educational community today to share ideas and experiences on how to best approach the design challenges mentioned above, so as to support a wider and more effective adoption of the flipped classroom model in educational settings.

\section{References}

[1] Lakmal, A. and Dawson, P. (2015). "Motivation and cognitive load in the flipped classroom: definition, rationale and a call for research." Higher Education Research \& Development 34(1), 1-14.

[2] Ronchetti, M. (June 2010), "Using video lectures to make teaching more interactive", International Journal of Emerging Technologies in Learning (iJET).

[3] Topp G. (2011), "Flipped classrooms take advantage of technology", USA Today.

[4] Bergmann, J., \& Sams, A. (2012). Flip your classroom: reach every student in every class every day. Washington, DC: International Society for Technology in Education.

[5] Bennett, B., Spencer, D., Bergmann, J., Cockrum, T., Musallam, R., Sams, A., Fisch, K., \& Overmyer, J. (2013). "The flipped classroom manifest"

[6] Alvarez, B. (2011). "Flipping the classroom: Homework in class, lessons at home". Education Digest: Essential Readings Condensed For Quick Review, 77 (8): 18-21. 